\title{
Jaarverslag cystectomieregistratie NVU 2017
}

\author{
Henk van der Poel ${ }^{1}$ Igle-Jan de Jong • Werkgroep oncologische urologie (WOU) van de NVU
}

Published online: 4 December 2018

(c) The Author(s) 2018

\section{Samenvatting}

In de www.nvukwaliteit.nl registratie van de Nederlandse Vereniging voor Urologie (NVU) is het aantal ingevoerde cystectomieën de afgelopen jaren stabiel gebleven. Wel is er een trend naar meer robot-geassisteerde ingrepen maar deze is ruim minder dan de helft van het totaal. Er is een dalende trend naar het aantal ingevoerde orthotope urinedeviaties en een dalende trend van de 30-dagenmortaliteit.

Trefwoorden www.nvukwaliteit.nl $\cdot$ registratie $\cdot$ cystectomieën

\section{Annual report cystectomy-registry Dutch Association of Urology 2017}

\begin{abstract}
In the www.nvukwalit.nl registry of the Dutch Association of Urology the number of reported cystectomies remains stable of recent years. A clear trend towards more frequent use of robot-assistance during the procedure is reported but still the majority of cases is performed with the open surgery technique. A decreasing 30-days mortality rate is reported.
\end{abstract}

Keywords www.nvukwalit.nl $\cdot$ registry $\cdot$ cystectomy

\section{Aantal ingrepen}

De afgelopen jaren is er een stabiel aantal geregistreerde cystectomieën in de database. In 2017 werden in $37 \mathrm{kli}-$ nieken cystectomieën uitgevoerd (dat is overigens meer klinieken dan er prostatectomieën uitvoeren, conform ook de bevindingen in 2016). Opvallend is de sterke spreiding in aantal ingrepen per kliniek (fig. 1). De regressieanalyse en statische vergelijkingen werden uitgevoerd met SPSS 22. Niet alle data zijn in de registratie volledig ingevoerd. Data over het aantal klierdissecties bijvoorbeeld ontbreken in een aantal gevallen en zijn daarom niet meegenomen in de analyse.

Wel is opvallend dat er wat minder orthotope deviaties worden aangelegd in de meer recente jaren (fig. 2). Het aantal robotgeassisteerde cystectomieën neemt iets toe, maar is ruim minder dan de helft van het totale aantal cystectomieën (fig. 3).

dr. Henk van der Poel

h.vd.poel@nki.nl

1 Nederlandse Vereniging voor Urologie, Utrecht, Nederland
Opvallend hierbij is dat met name het aantal open orthotope deviaties lijkt te verminderen, terwijl het aantal robotgeassisteerde orthotope deviaties stabiel blijft, maar nog altijd minder is dan bij de open uitgevoerde cystectomieën (fig. 4).

\section{Lymfeklierdissecties}

In 2017 werd een onderscheid gemaakt tussen een beperkte klierdissectie van de obturator loge, een standard klierdissectie (tot de ureter-vaatkruising) en een uitgebreide klierdissectie (tot de aorta bifurcatie). Voor de verschillende typen ingreep: open, laparoscopisch (al dan niet met conversie), en robotgeassisteerd waren de percentages zoals weergegeven in tab. 1 .

\section{Perioperatieve gegevens}

Mediaan bloedverlies was wat minder bij de (robotgeassisteerde) laparoscopische ingrepen en het minst bij de robotgeassisteerde Bricker deviatie (fig. 5). 
Tabel 1 Percentage klierdissecties per type ingreep in 2017

\begin{tabular}{|c|c|c|c|c|c|c|}
\hline & $\begin{array}{l}\text { soort ingreep } \\
\text { open proce- } \\
\text { dure }\end{array}$ & laparoscopie & $\begin{array}{l}\text { laparoscopie met con- } \\
\text { versie }\end{array}$ & onbekend & robotchirurgie & totaal \\
\hline $\begin{array}{l}\text { beperkt (obturatorius- } \\
\text { holte bdz.) }\end{array}$ & $2,1 \%$ & $0,0 \%$ & $0,0 \%$ & $0,0 \%$ & $2,3 \%$ & $2,0 \%$ \\
\hline $\begin{array}{l}\text { standaard (obtu- } \\
\text { ratoriusholte } \\
\text { bdz. + Iliacaaltraject } \\
\text { bdz. tot aan de ureter) }\end{array}$ & $73,5 \%$ & $11,4 \%$ & $50,0 \%$ & $85,7 \%$ & $77,5 \%$ & $72,8 \%$ \\
\hline $\begin{array}{l}\text { uitgebreid (tot aan de } \\
\text { aortabifurcatie presa- } \\
\text { craal) }\end{array}$ & $16,8 \%$ & $88,6 \%$ & $50,0 \%$ & $0,0 \%$ & $17,5 \%$ & $19,3 \%$ \\
\hline geen & $7,0 \%$ & $0,0 \%$ & $0,0 \%$ & $4,8 \%$ & $2,3 \%$ & $5,2 \%$ \\
\hline
\end{tabular}

Maar de operatieduur was langer voor de robotgeassisteerde cystectomieën (fig. 6).

Terwijl de opnameduur na een (robotgeassisteerde) laparoscopische cystectomie wat korter was dan na een open ingreep (fig. 7). De spreiding was groot, ook binnen de verschillende groepen, en het verschil in mediane opnameduur tussen de open- en robotgeassisteerde procedures was minder dan drie dagen.

Per kliniek was er een groot verschil in gerapporteerd gemiddeld bloedverlies (fig. 8). Het bloedverlies tijdens de operatie per kliniek was significant gecorreleerd met het percentage minimaal invasief uitgevoerde ingrepen (Spearman $\mathrm{r}=0,572 ; p<0,001)$.

Klinieken met meer ingrepen rapporteerden minder bloedverlies peroperatief, waarbij klinieken die in 2017 meer dan 30 ingrepen uitvoerden gemiddeld nooit meer dan 1 liter bloedverlies hadden (fig. 9).

Ook de gemiddelde opnameduur verschilde per kliniek (fig. 10).

Ziekenhuizen met minder dan 20 ingrepen in 2017 hadden mediaan meer bloedverlies en een langere opnameduur, maar de spreiding tussen klinieken was groter dan het verschil tussen de groepen (fig. 11).

Zestien van de 37 (43\%) klinieken voerden robotgeassisteerde cystectomieën uit (fig. 12).

Van de 37 klinieken voerden er 26 (70\%) orthotope deviaties uit terwijl in zes klinieken de gegevens over het type deviatie niet waren aangegeven (fig. 13).

\section{Mortaliteit}

De 30- en 90-dagenmortaliteit zijn weergegeven in fig. 14. Hierbij kan onvoldoende geverifieerd worden of alle gegevens van de ziekenhuizen zonder mortaliteit een onderrapportage betreffen. Wel is opvallend dat de mortaliteit in een aantal klinieken ver boven het gemiddelde ligt dat in de literatuur wordt gerapporteerd (<3\%). In 2017 overleden 20 patiënten binnen 30 dagen en 17 patiënten tussen dag 30 en dag 90 (fig. 14).

$\mathrm{Er}$ is een neerwaartse trend van de gerapporteerde 30 dagen-, maar niet van de gerapporteerde 90-dagenmortaliteit (fig. 15).

Voor de gehele database ( $n=7.412$ patiënten) is de 30 dagenmortaliteit voor robotgeassisteerde en open cystectomieën gelijk, maar lijkt de mortaliteit na laparoscopie wat hoger te zijn (fig. 16).

Met name de hoge 90-dagenmortaliteit na robotgeassisteerde orthotope deviaties valt op: $>2 \times$ hoger dan na een open ingreep en ook hoger dan na een robotgeassisteerd uitgevoerde Bricker-deviatie. De aantallen patiënten in deze analyse zijn laag, wat conclusies moeilijk maakt, maar nader onderzoek hiernaar is gewenst (fig. 17). 
Figuur 1 Aantal ingevoerde cystectomieën per kliniek in 2017

Figuur 2 Aantal cystectomieën per deviatietype
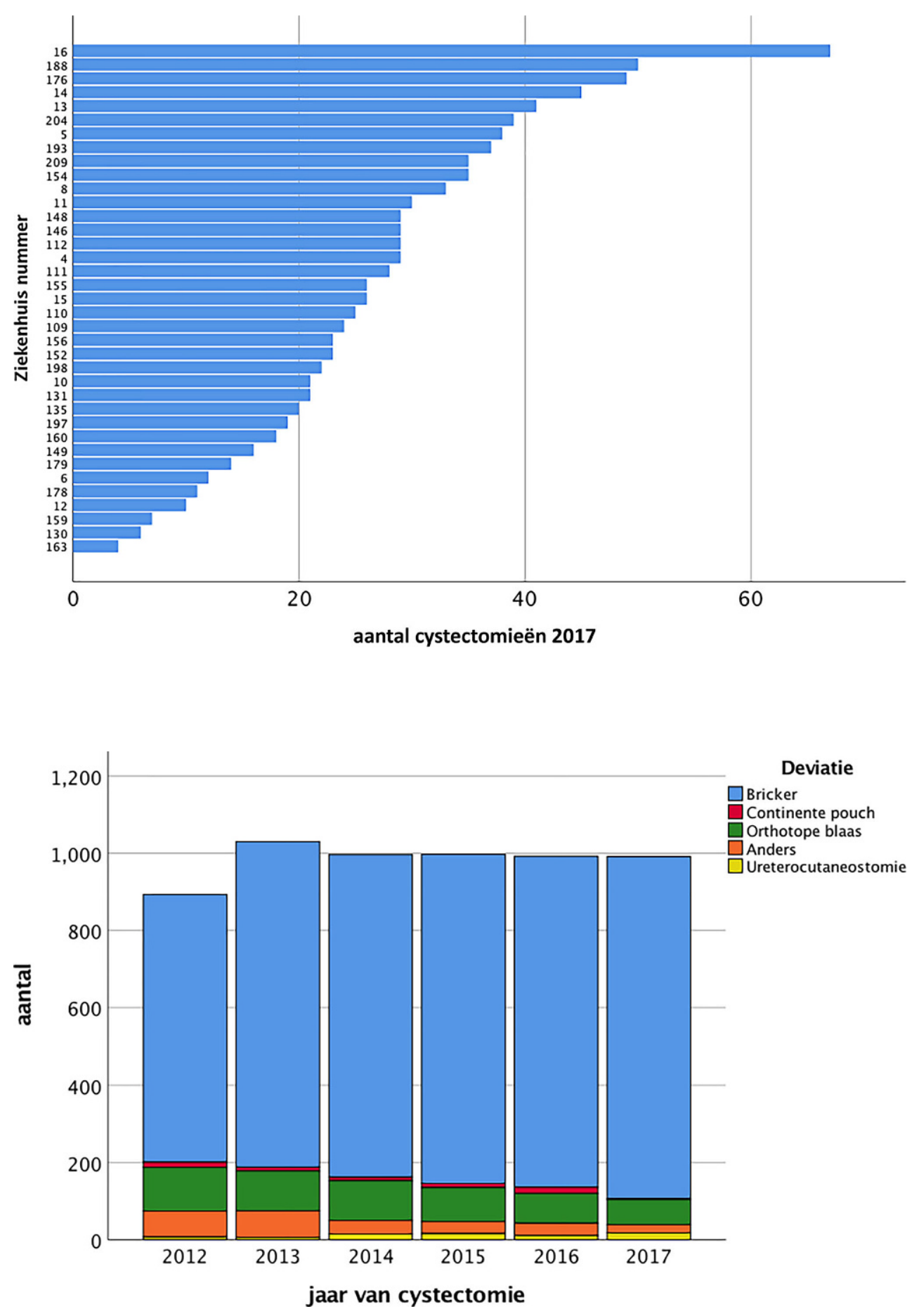
Figuur 3 Soort cystectomie per jaar

Figuur 4 Type deviatie per soort cystectomie per jaar
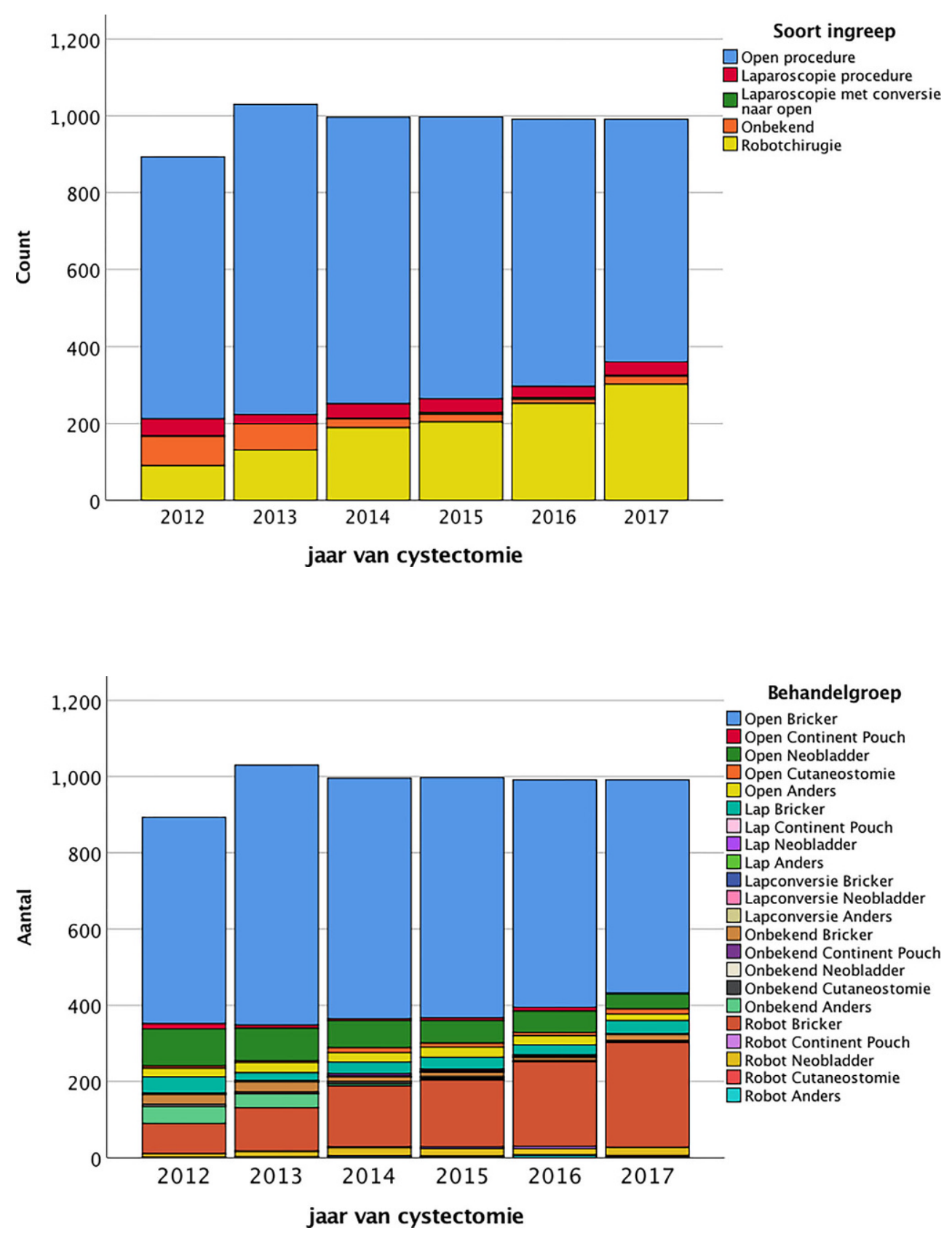
Figuur 5 Boxplot (mediaan) voor bloedverlies per type cystectomie en deviatie

Figuur 6 Operatieduur in minuten per type ingreep en type deviatie in 2017

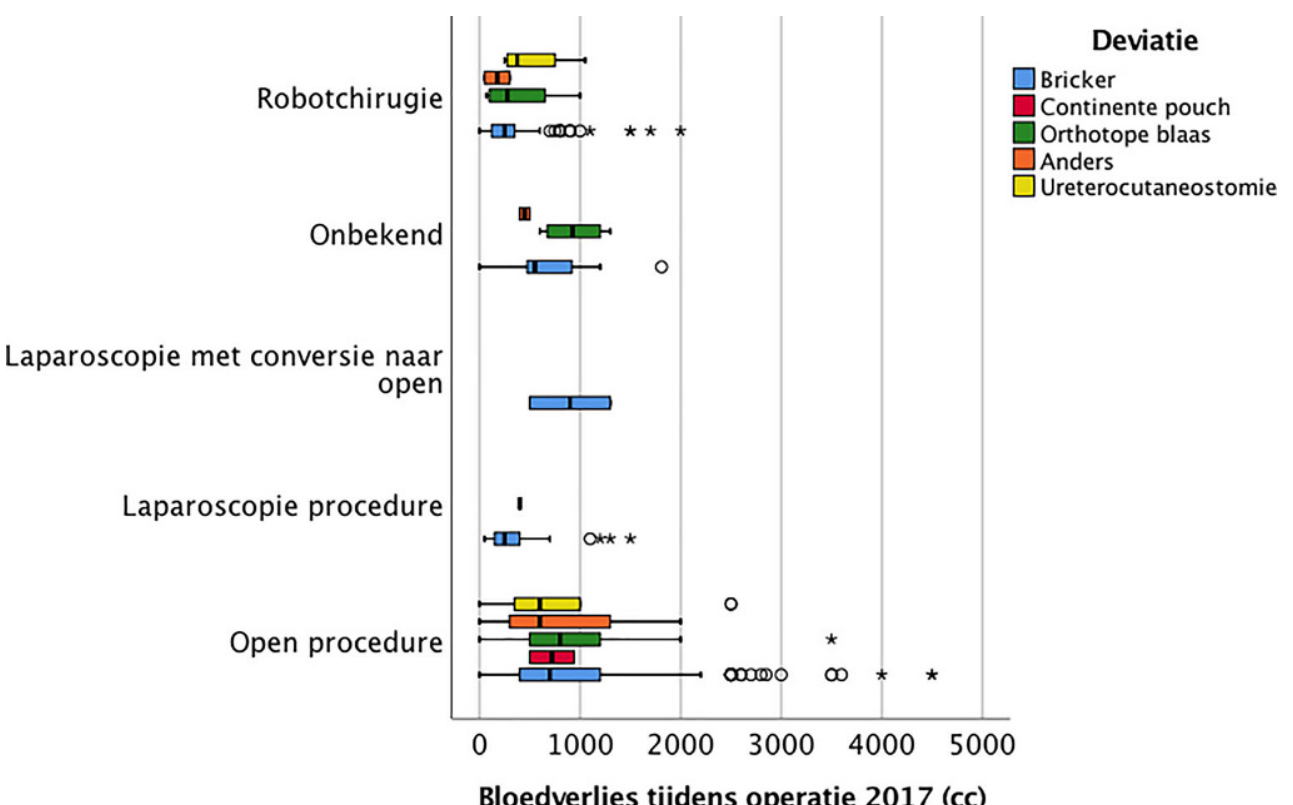

Bloedverlies tijdens operatie 2017 (cc)

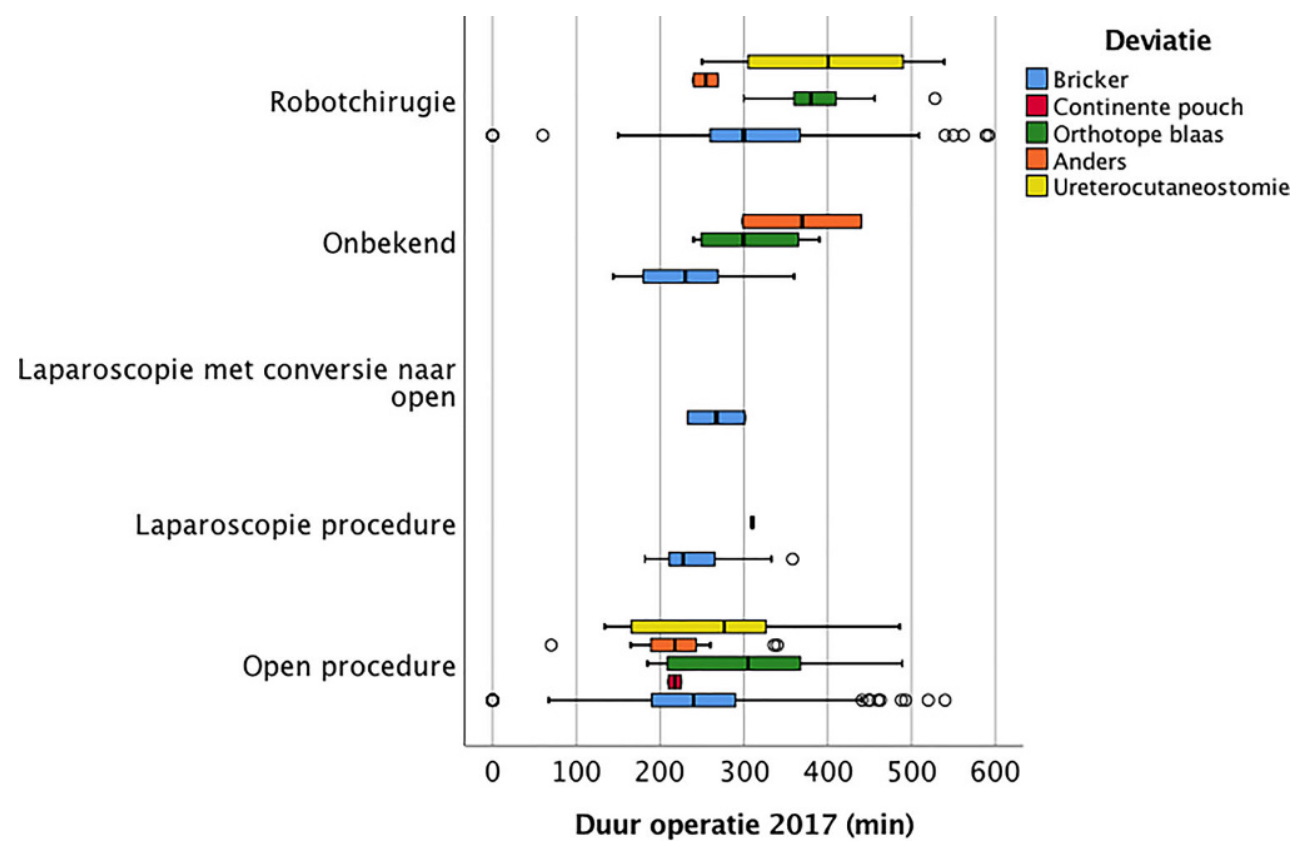


Figuur 7 Opnameduur in dagen per type ingreep en type deviatie in 2017

Figuur 8 Gemiddeld bloedverlies per kliniek in 2017
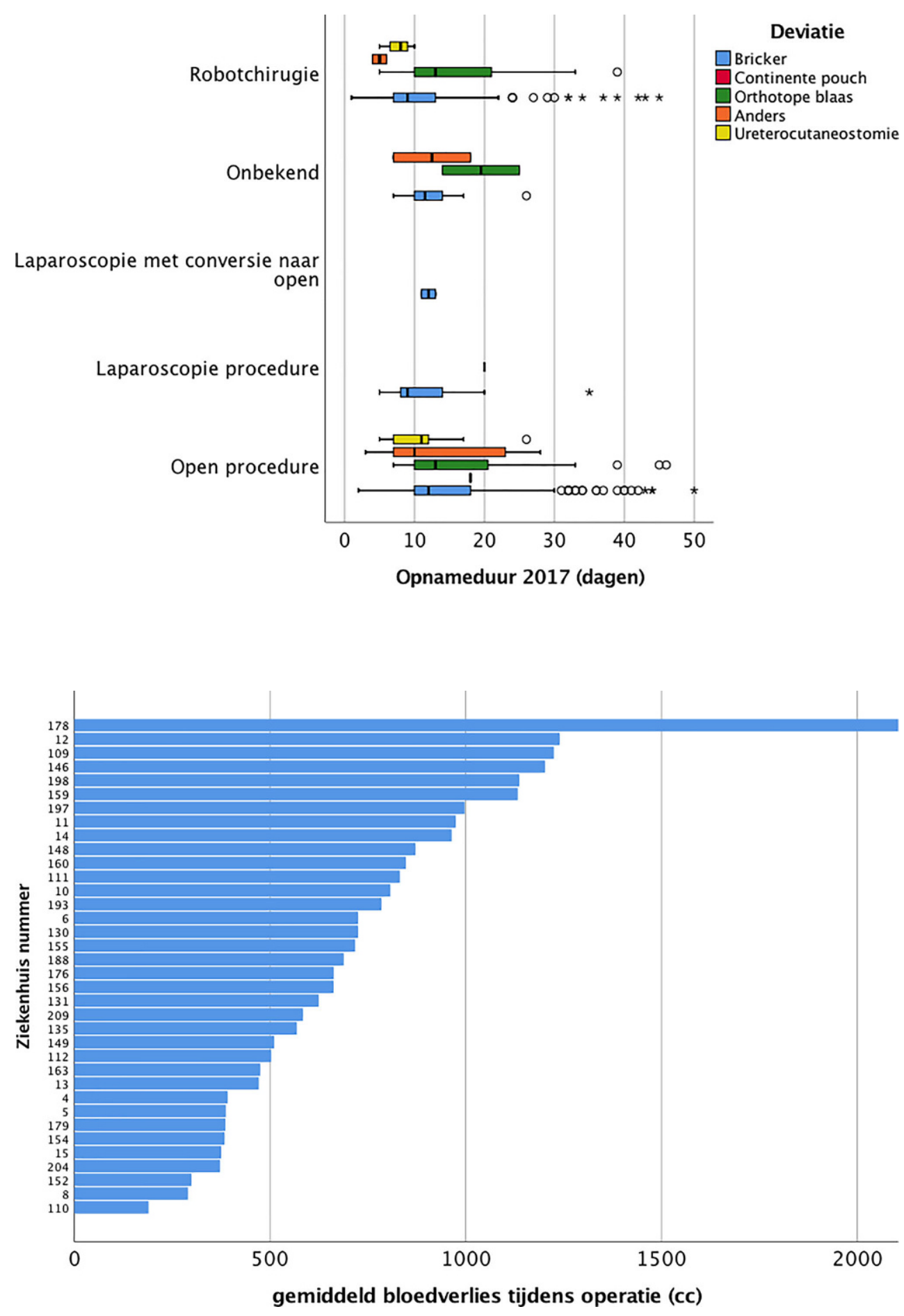
Figuur 9 Gemiddeld bloedverlies afgezet tegen het aantal ingevoerde cystectomieën in 2017

Figuur 10 Gemiddeld aantal gerapporteerde opnamedagen per kliniek in 2017
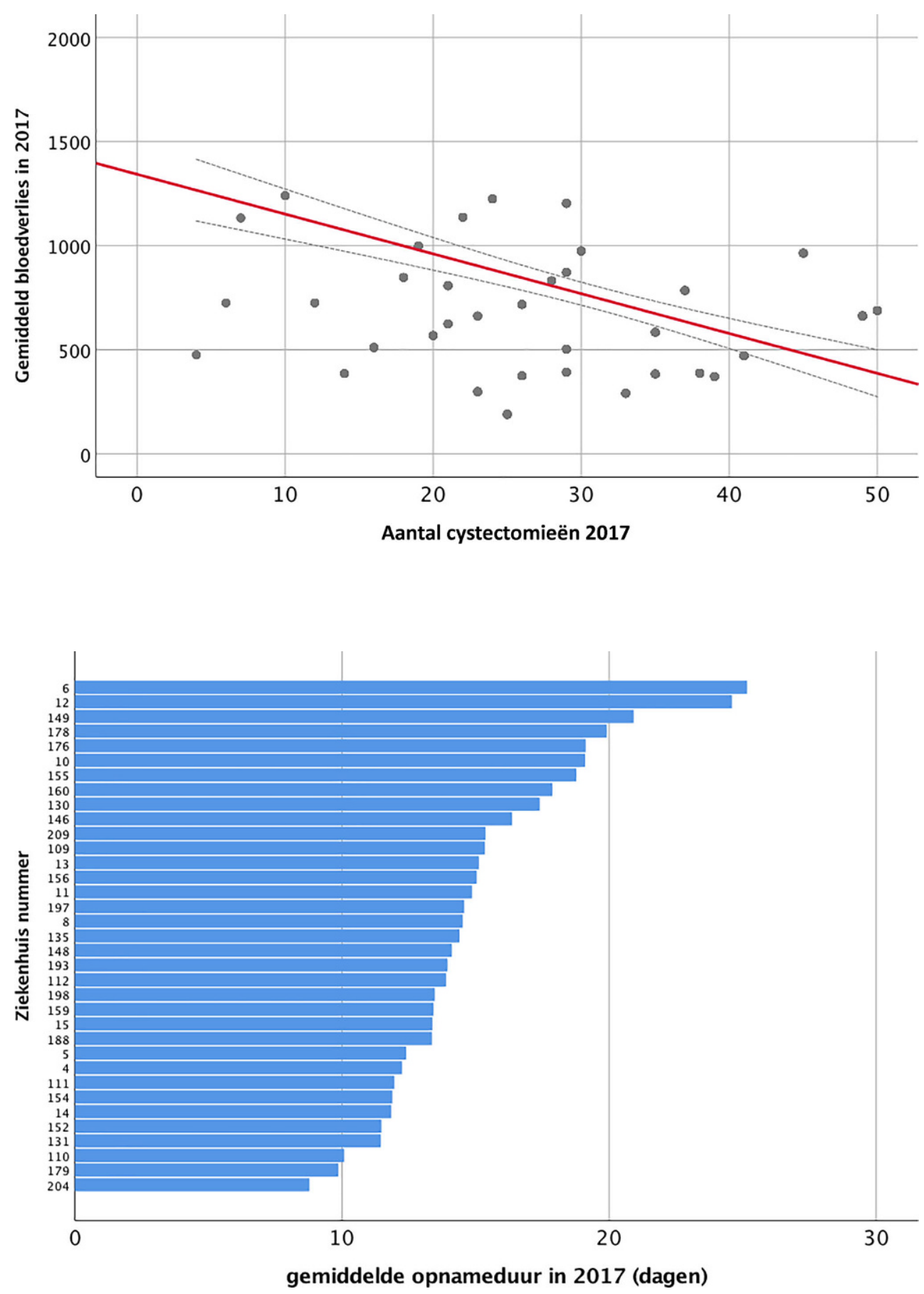
Figuur 11 Boxplot voor bloedverlies per aantal verrichte cystectomieën per ziekenhuis in 2017 (a) en het aantal ligdagen (b)
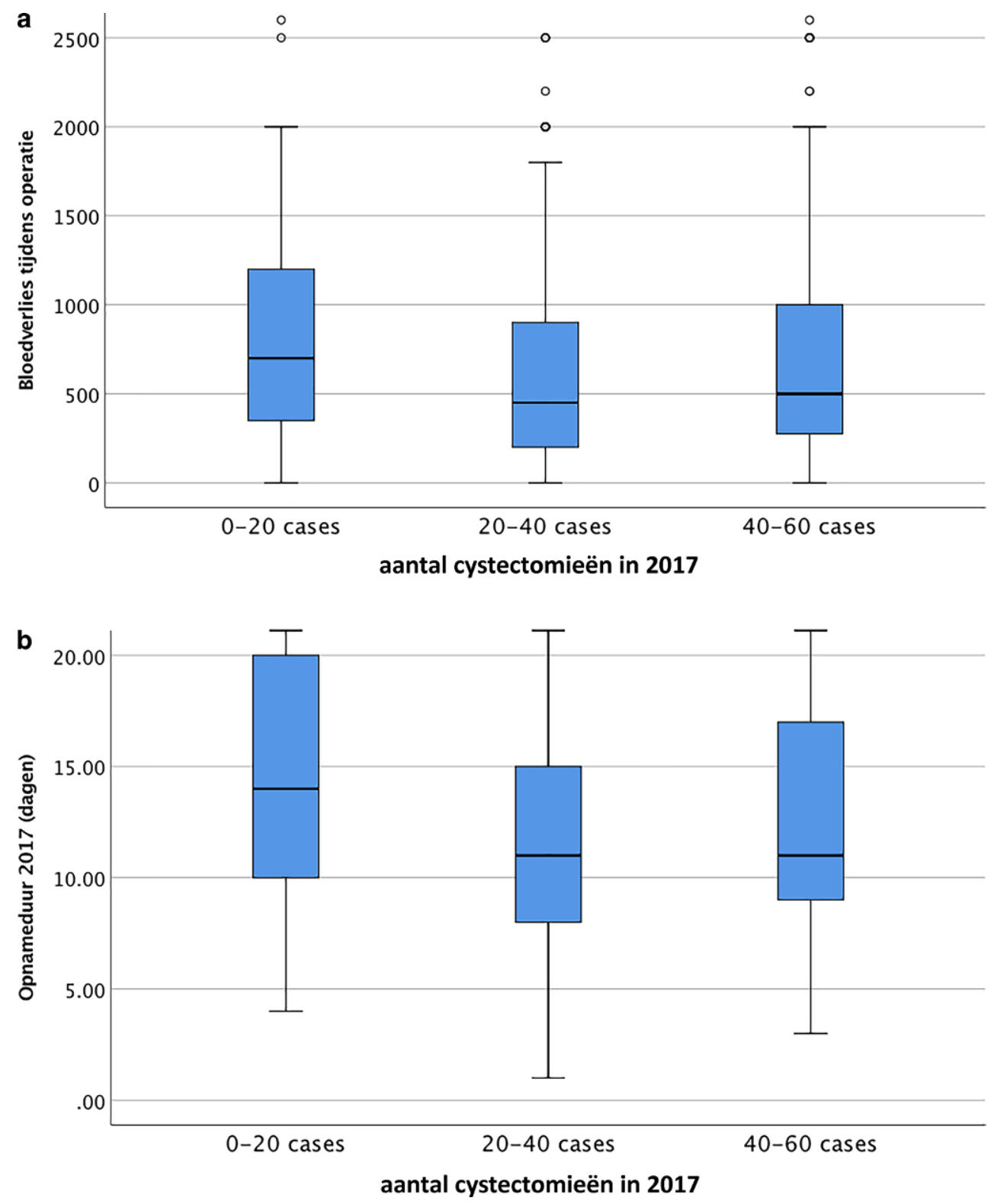
Figuur 12 Het aantal cystectomieën ingevoerd per kliniek in 2017 uitgesplitst naar type ingreep

Figuur 13 Aantal ingevoerde ingrepen per kliniek uitgesplitst naar type deviatie (van onder meer kliniek 16 ontbrak het type ingreep)

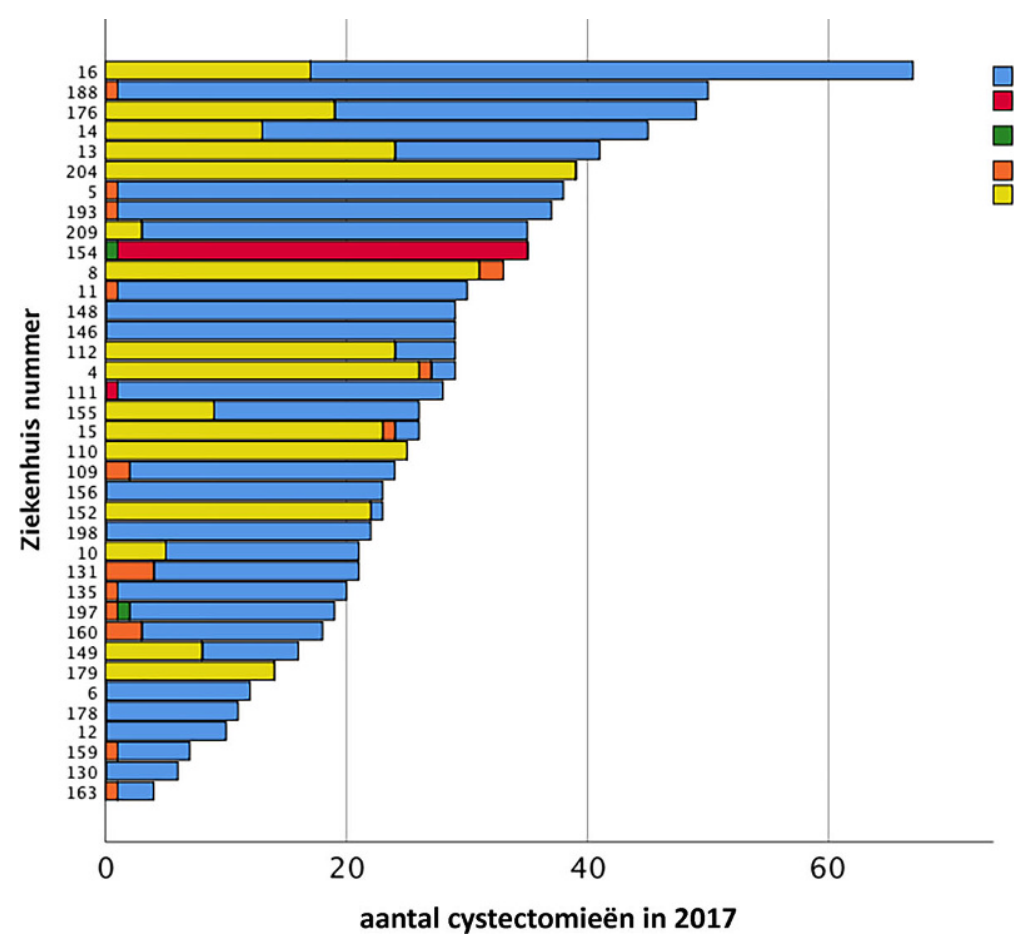

Soort cystectomie

Open procedure

Laparoscopie procedure

Laparoscopie met conversie

Onbekend

Robotchirugie

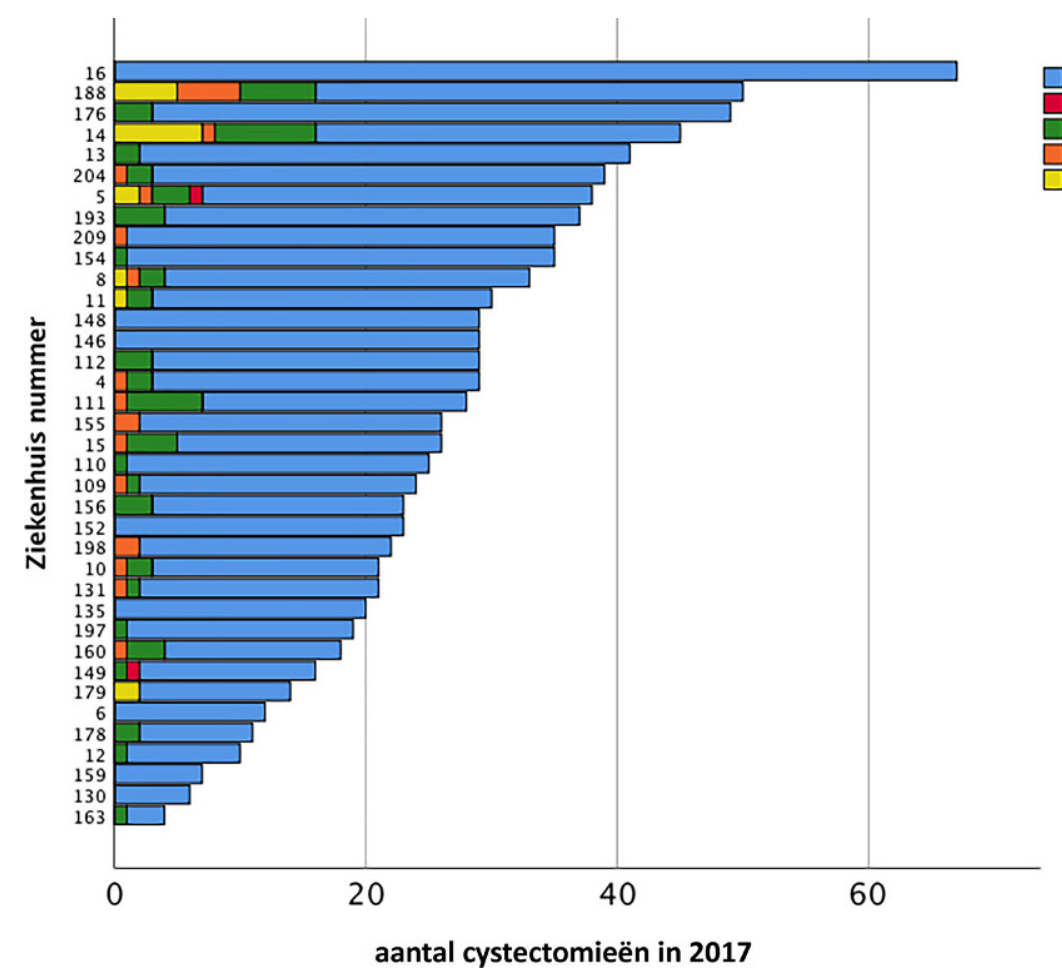

Deviatie

Bricker

Continente pouch

Orthotope blaas

Anders

Ureterocutaneostomie 
Figuur 14 De 30 dagen- (a) en 90 dagen- (b) mortaliteit na cystectomie in 2017
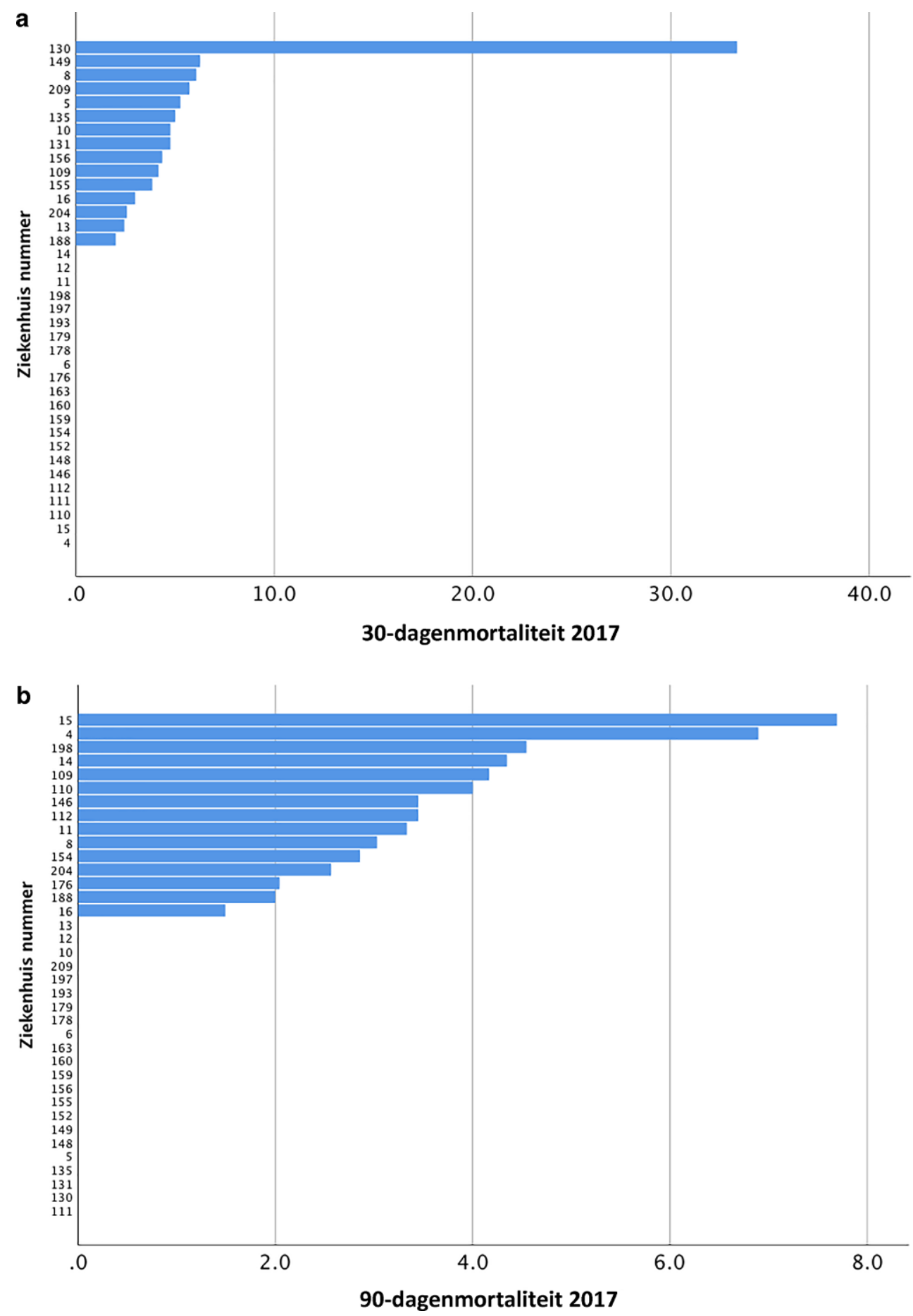
Figuur 15 De 30-dagen- (a) en 90-dagen- (b) mortaliteit in de afgelopen jaren a
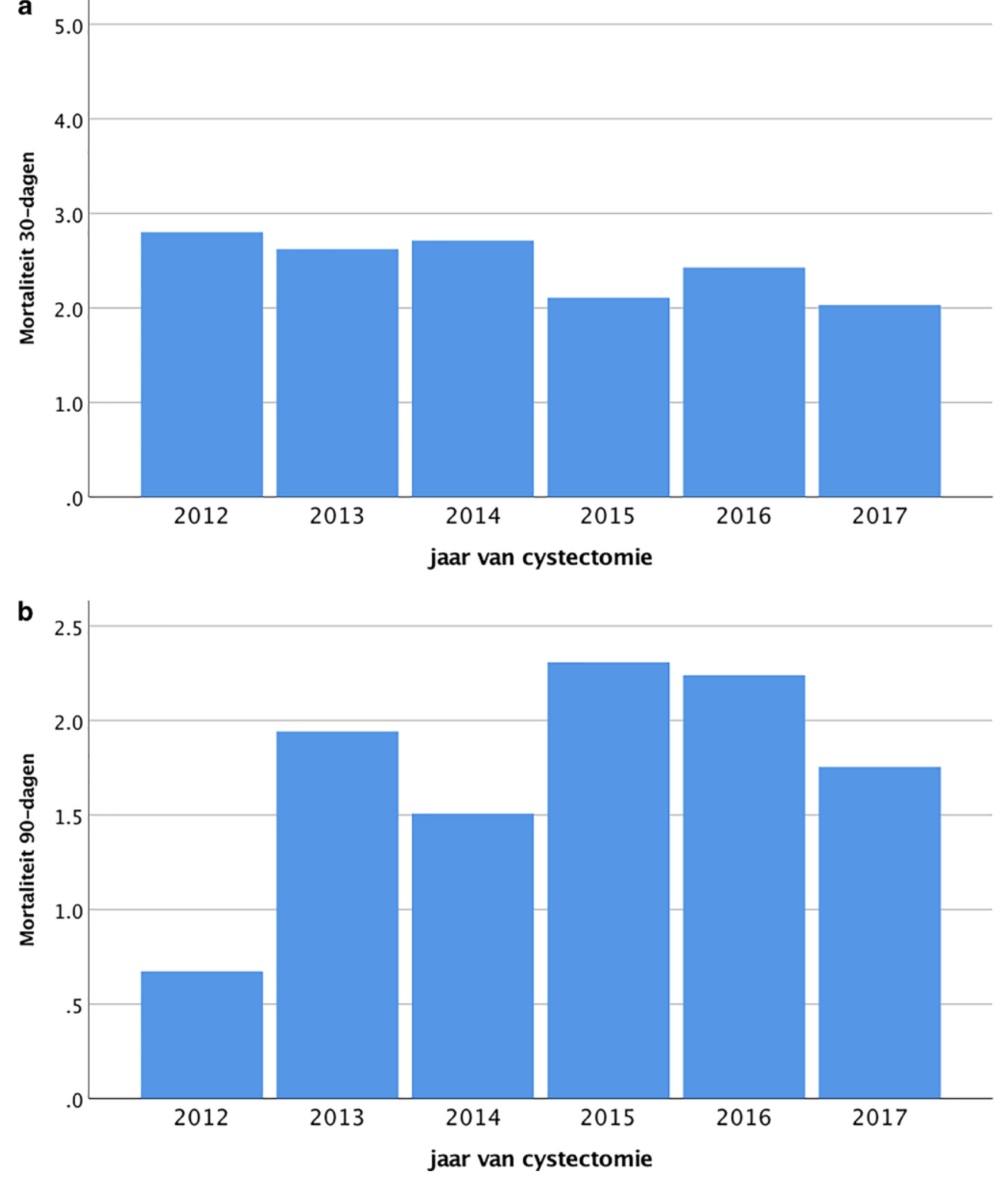
Figuur 16 De 30-dagenmortaliteit per type ingreep en type deviatie

Figuur 17 De 90-dagenmortaliteit per type ingreep en type deviatie
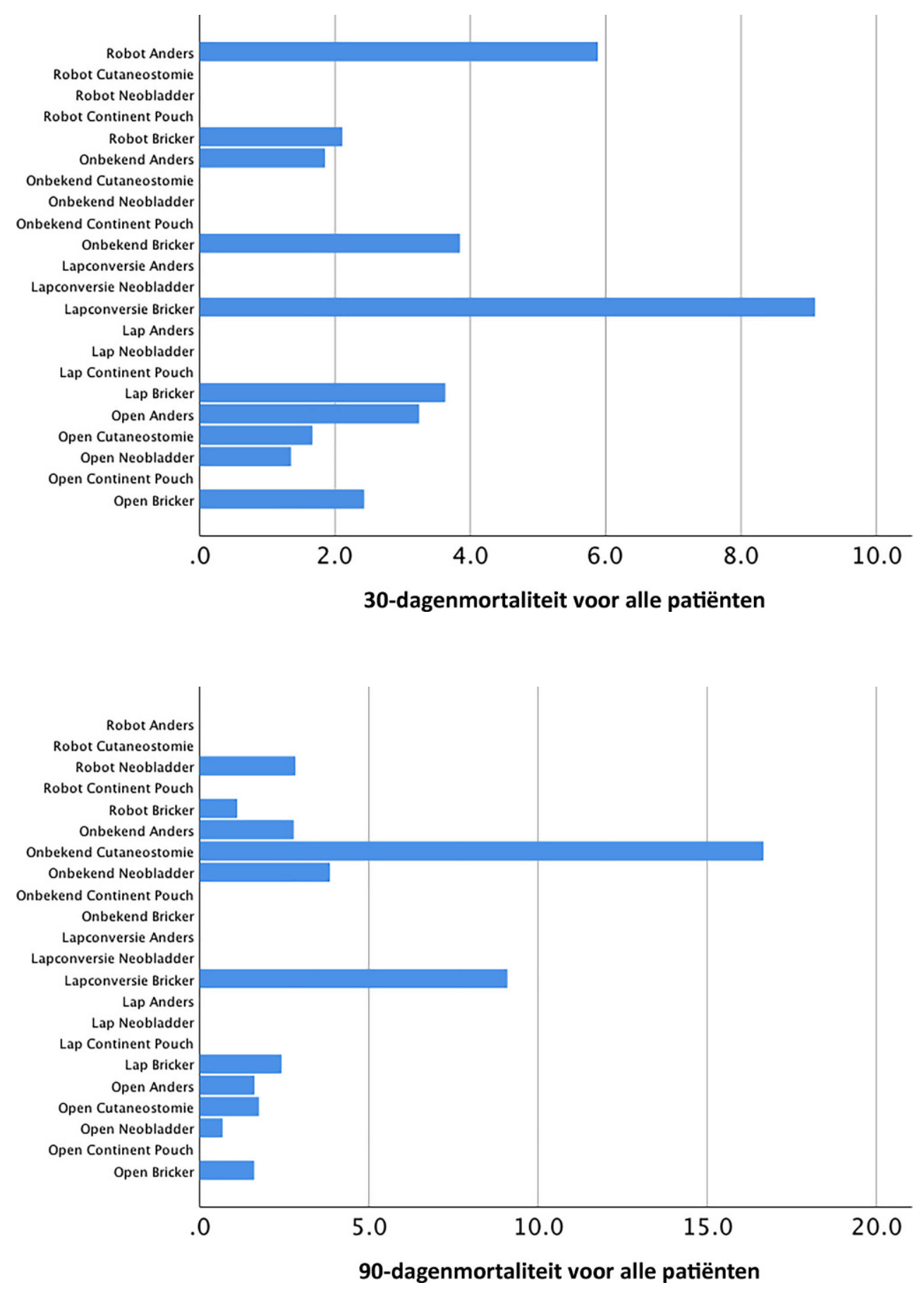

\section{Conclusie}

Het aantal cystectomieën dat is ingevoerd in de NVU-registratie is de laatste jaren stabiel gebleven. Er lijkt een trend te zijn naar het uitvoeren van minder orthotope deviaties. $\mathrm{Er}$ is een trend naar verbetering van de mortaliteit in de eerste 30 dagen.
Open Access This article is distributed under the terms of the Creative Commons Attribution 4.0 International License (http:// creativecommons.org/licenses/by/4.0/), which permits unrestricted use, distribution, and reproduction in any medium, provided you give appropriate credit to the original author(s) and the source, provide a link to the Creative Commons license, and indicate if changes were made.

dr. Henk van der Poel uroloog

prof. dr. Igle-Jan de Jong uroloog 